\title{
Dynamics of toxigenic Clostridium perfringens colonisation in a cohort of prematurely born neonatal infants
}

\author{
Alexander G. Shaw ${ }^{1 *}$ (D), Emma Cornwell ${ }^{2+}$, Kathleen Sim² ${ }^{2}$ Hannah Thrower ${ }^{2}$, Hannah Scott ${ }^{2}$, Joseph C. S. Brown ${ }^{3}$,
} Ronald A. Dixon ${ }^{3}$ and J. Simon Kroll ${ }^{2}$

\begin{abstract}
Background: Clostridium perfringens forms part of the human gut microbiota and has been associated with lifethreatening necrotising enterocolitis (NEC) in premature infants. Whether specific toxigenic strains are responsible is unknown, as is the extent of diversity of strains in healthy premature babies. We investigated the C. perfringens carrier status of premature infants in the neonatal intensive care unit, factors influence this status, and the toxic potential of the strains.
\end{abstract}

Methods: C. perfringens was isolated by culture from faecal samples from 333 infants and their toxin gene profiles analysed by PCR. A survival analysis was used to identify factors affecting probability of carriage. Competitive growth experiments were used to explore the results of the survival analysis.

Results: $29.4 \%$ of infants were colonized with C. perfringens before they left hospital. Three factors were inversely associated with probability of carriage: increased duration of maternal milk feeds, CPAP oxygen treatment and antibiotic treatment. C. perfringens grew poorly in breast milk and was significantly outperformed by Bifidobacterium infantis, whether grown together or separately. Toxin gene screening revealed that infants carried isolates positive for collagenase, perfringolysin $O$, beta 2 , beta, bec $A / B$, net $B$ and enterotoxin toxin genes, yet none were observed to be associated with the development of NEC.

Conclusions: Approximately a third of preterm infants are colonised 3 weeks after birth with toxin gene-carrying $\mathrm{C}$. perfringens. We speculate that increased maternal breast milk, oxygen and antibiotic treatment creates an environment in the gut hostile to growth of $C$. perfringens. Whilst potentially toxigenic $C$. perfringens isolates were frequent, no toxin type was associated with NEC.

Trial registration: clinicaltrials.gov NCT01102738, registered 13th April 2010.

Keywords: Clostridium perfringens, Breast milk, Toxins, Necrotising enterocolitis

\section{Background}

Clostridium perfringens is an archetypal pathosymbiont, forming part of the gut commensal microbiota in humans and animals, but also capable of producing devastating disease by way of its toxin arsenal. This anaerobic, Gram-positive spore-former is the leading cause of traumatic gas gangrene in humans [1] and one of the

\footnotetext{
* Correspondence: a.shaw@imperial.ac.uk

${ }^{\dagger}$ Alexander G. Shaw and Emma Cornwell contributed equally to this work. 'Department of Infectious Disease Epidemiology, Imperial College London, London, UK

Full list of author information is available at the end of the article
}

most common causes of food poisoning, responsible for an estimated 1 million cases in the US each year [2]. $C$. perfringens has been linked to necrotizing enterocolitis (NEC) - an inflammatory bowel disease with high mortality - in preterm neonates [3-7]. This condition has several predisposing factors; an immature gut, the presence of bacteria and potentially hypoxia and ischemia around the site of pathology [3]. A single causative organism has however remained elusive, with studies having found associations with other components of the gut microbiota such as the Enterobacteriaceae [7-9]. The toxic potential of $C$. perfringens in relation to the genesis

(c) The Author(s). 2020 Open Access This article is distributed under the terms of the Creative Commons Attribution 4.0 International License (http://creativecommons.org/licenses/by/4.0/), which permits unrestricted use, distribution, and reproduction in any medium, provided you give appropriate credit to the original author(s) and the source, provide a link to the Creative Commons license, and indicate if changes were made. The Creative Commons Public Domain Dedication waiver (http://creativecommons.org/publicdomain/zero/1.0/) applies to the data made available in this article, unless otherwise stated. 
of NEC remains intriguing. A role has also been proposed for Clostridium spp. in infant atopy and allergic sensitisation $[10,11]$ and autism $[12,13]$.

Previous studies investigating clostridial carriage in apparently healthy premature neonates have often involved small sample sizes, $[14,15]$ or reflected the opportunity to study control groups recruited for studies of topics such as the effect of different feeding or probiotic regimes [16]. We have recruited a large cohort of wellcharacterised premature neonates who were treated according to standard care protocols and provided faecal samples from birth until their departure from hospital. The microbiota profiles of these neonates were previously characterised by next-generation sequencing which identified significantly higher levels of $C$. perfringens in a subset of infants who were diagnosed with NEC compared to controls [7]. In the present current study, our first aim has been to use a culture-dependent approach to build up a collection of neonatal C. perfringens isolates and establish colonisation dynamics in the cohort. We have gone on to relate this to perinatal factors which we hypothesise will influence rates of carriage.

We have investigated the toxin gene carriage rates in these neonatal $C$. perfringens isolates. $C$. perfringens strains encode a formidable arsenal of more than 20 toxins $[17,18]$ - many with cytotoxic effects - including the well-characterised alpha toxin, beta toxin, and the $C$. perfringens enterotoxin (CPE, encoded by the cpe gene), which are respectively implicated in the human diseases gas gangrene, necrotic enteritis (Pigbel) and food poisoning (see Supplementary Material 1). Previous studies have shown that toxigenic $C$. perfringens strains are present in healthy adult populations (see Supplementary Material 1), but there is a lack of data for neonatal populations and also for toxins other than the 4 major and 2 minor toxins that make up standard multiplex PCR screens for assigning toxin type and investigating cases of food poisoning [19]. We here report the result of screening for the presence of 11 toxin genes; $c p a, c p b$, etx, itx, cpe, cpb2, netB, becA, becB, pfoA and colA (see Supplementary Material 1 for characterisations) in our neonatal isolates, seeking possible associations with NEC and establishing the normal clostridial toxin gene carriage rates in premature infants during their stay on the neonatal intensive care unit.

\section{Methods}

\section{Study population}

Infants born $<32$ weeks gestation admitted to an Imperial College Healthcare National Health Service Trust neonatal intensive care unit (St Mary's Hospital, Queens Charlotte's and Chelsea Hospital) between January 2010 and December 2011 were eligible for inclusion in our ecological study "Defining the Intestinal Microbiota in
Premature Infants" (The Neonatal Microbiota (NeoM) Study). Both hospitals have identical antibiotic and feeding protocols and staff members rotate between sites. Detailed daily clinical records were collected for all participants. Of the 369 babies recruited, 333 provided faecal samples for analysis in the present study (a total of 1399 samples).

\section{Sample collection}

We collected every faecal sample produced by participants between admission and discharge. Samples were collected by nursing staff from diapers using a sterile spatula and placed in a sterile DNAase-, RNAase-free Eppendorf tube. These were stored at $-20^{\circ} \mathrm{C}$ within $2 \mathrm{~h}$ of collection and were transferred to $-80^{\circ} \mathrm{C}$ storage within 5 days. Approximately one sample per week was selected for culture.

\section{Clostridium culture protocol}

Selective culture for clostridia species was performed using an ethanol shock methodology to eliminate nonspore forming organisms [20]. $25 \mathrm{mg}$ of faeces was added to $500 \mu \mathrm{l}$ of cooked meat broth (Oxoid) and $500 \mu \mathrm{l}$ of $100 \%$ ethanol and vortexed for $10 \mathrm{sec}$ before incubating for $30 \mathrm{~min}$ at room temperature. A sterile loop was dipped in the supernatant and streaked onto a fastidious anaerobic agar plate supplemented with $0.1 \%$ sodium taurocholate hydrate (Sigma) and 5\% defibrinated sheep blood (Oxoid). Plates were incubated anaerobically at $37^{\circ} \mathrm{C}$ for $48 \mathrm{~h}$ in an Oxoid 2.51 AnaeroJar plus AnaeroGen sachet. Resulting colonies were examined and for each morphologically distinct isolate, four colonies were subcultured by streaking onto Colombia agar with sheep blood (Oxoid) plates which were incubated anaerobically at $37^{\circ} \mathrm{C}$ for $48 \mathrm{~h}$. Single colonies were used for identification to the species level by matrix-assisted laser desorption/ ionization-time of flight (MALDI-TOF) using a Bruker Microflex LT (Bruker Daltonics), and the remainder of the subculture stored in $70 \%$ brain heart infusion (BHI) broth (Oxoid), 30\% glycerol (Sigma) at $80^{\circ} \mathrm{C}$.

\section{Toxin typing of Clostridium perfringens by polymerase chain reaction (PCR)}

PCR reactions were performed to detect $c p a, c p b, i A$, etx, cpe and $c p b 2$ (multiplex PCR), becA and becB (duplex PCR) and netB, pfoA, and colA (single PCR) and visualised by gel electrophoresis. For details see Supplementary Material 2.

\section{Breast milk growth competition experiment}

Bifidobacterium infantis (NCIMB 702255 - isolated from infant intestine), and Clostridium perfringens isolated from the faeces of an infant enrolled in our study 
were cultured either in Wilkins-Chalgren broth (WCB) (Oxoid) supplemented with $5 \mathrm{~g} / \mathrm{l}$ soya peptone (Oxoid), or human breast milk. Three donors gave breast milk on three occasions, for which informed consent was obtained and standardised expression protocols used. Breast milk was expressed on average $16 \mathrm{~h}$ before each experiment, was kept refrigerated at all times, and had a commensal microbial load (anaerobic) below the NICErecommended limit $\left(10^{5}\right.$ colony forming units $(\mathrm{CFU}) / \mathrm{ml}$ total viable organisms or $10^{4} \mathrm{CFU} / \mathrm{ml}$ Enterobacteriaceae or Staphylococcus aureus) [21], which was calculated by plating directly onto Colombia agar with sheep blood (Oxoid) and incubating for $48 \mathrm{~h}$ at $37^{\circ} \mathrm{C}$, followed by species identification using MALDI-TOF. The majority of organisms found in this manner were Staphylococcus and Actinomyces spps. Staphylococcus spp. were grown in every breast milk sample, whilst Actinomyces spp. were found in the milk of only one mother (see Supplementary Material 3). For bacterial counts, C. perfringens was grown on Tryptose Sulphite Cycloserine (TSC) agar plates (Oxoid) [22], and incubated for $24 \mathrm{~h}$ at $37^{\circ} \mathrm{C}$, and B. infantis on Bifidus Selective Medium (BSM) agar plates (Sigma) incubated for $48 \mathrm{~h}$ at $37^{\circ} \mathrm{C}$. All cultivation was performed under anaerobic conditions using an Oxoid 2.51 AnaeroJar plus AnaeroGen sachet in a shaking or static $37^{\circ} \mathrm{C}$ incubator.

Bacteria were grown in WCB to an optical density of approximately 0.7 , and approximately $1 \times 10^{4}$ colony forming units (CFUs) added to $2.5 \mathrm{ml}$ of breast milk or $2.5 \mathrm{ml}$ of WCB in $15 \mathrm{ml}$ bioreactor tubes (TTP). Media were inoculated with $C$. perfringens or B. infantis (monoculture), or both (co-culture). C. perfringens and $B$. infantis were enumerated after $20 \mathrm{~h}$ incubation by plating dilutions in triplicate onto TSC agar and BSM agar respectively. Breast milk from three different donors was used and experiments carried out in triplicate (to total nine experiments).

\section{Statistics}

Statistical analyses were performed in the $\mathrm{R}$ statistical package (version 3.3.1). A Cox Proportional-Hazard regression function from the 'survival' package was used for the survival analysis. An initial univariate analysis was performed to determine any significant relation between each clinical factor in Table 1 and C. perfringens colonisation (defined as the earliest faecal sample where C. perfringens was isolated). Factors found to remain significant after a multiple hypothesis (Bonferroni) correction were entered into an iterative multivariate model, with factors found to have a $p$ value of $>0.1$ being removed at each iterative step. Barnard's test was performed to detect associations between antibiotic use and breast milk feeds and long-term carriage, and between toxin genes and NEC development. Growth rate comparisons were performed using generalized linear models and the 'mass' package using both the mean fold-change for each experimental triplicate and the mean absolute change in CFU. $P$-values shown were derived from the fold-change models, with similar results by either metric.

\section{Results \\ C. perfringens incidence and clinical factors associated with its colonisation}

Faecal samples and complete clinical notes were available for 333 infants. The demographics of these babies are shown in Table 1. C. perfringens was isolated in faecal samples from 98 of the infants (29.4\%).

Colonisation data were used to predict the risk of colonisation of the infant gut by $C$. perfringens over time through a survival analysis (Fig. 1). By the day of life of the median stay on the neonatal unit for the cohort $(29$ days), a predicted $36 \%$ of infants would be colonised (95\% confidence band $25,43 \%$ ).

We next repeated the survival analysis with the aim of determining clinical variables (shown in Table 1) that were associated with $C$. perfringens colonisation. A series of univariate models were created and significantly associated variables (after multiple hypothesis correction) are shown in Table 2.

For each significant factor, values are provided at each of its quartiles to illustrate the spread of data. The exponentiated coefficients provide the change in risk of colonisation per unit of each factor. Risk change indicates the relative change in risk of colonisation between the minimum value $(0 \%)$ and the $75 \%$ quartile for a given clinical factor. Abbreviations: CI, confidence interval.

Given the potential for correlation between these variables, a multivariate survival analysis was used to identify a minimal set of clinical factors to best predict colonisation. Four factors were found to remain significant in this model, with associations between increased probability of $C$. perfringens colonisation and fewer days of CPAP with supplemental oxygen (CPAP oxygen), fewer days of maternal milk feeds (via feeding tube), fewer days of breast feeding and fewer days of antibiotics over the course of the infant's admission. The variation of colonisation probabilities when the infant cohort is divided into quartiles for each of these factors is shown in Fig. 2.

As the risk of colonisation for each infant is associated with the combined effects of each of these factors, we performed a multivariate analysis where each infant in the cohort was annotated either "low" ( $<=$ median) or "high" (>median) for each of the four factors. Multiple sets of analyses were run, illustrating the effects of higher than average measure of a single factor, or 
Table 1 Demographics of infants included in the analysis ( $N=$ 333)

\begin{tabular}{|c|c|}
\hline Demographics & Number \\
\hline \multicolumn{2}{|l|}{ Gestation } \\
\hline Mean gestation at birth in days (SD) & $197(16)$ \\
\hline Median gestation at birth in days (IQR) & $198(27)$ \\
\hline \multicolumn{2}{|l|}{ Birth weight } \\
\hline Mean birth weight in g (SD) & $\begin{array}{l}1079.5 \\
(340.8)\end{array}$ \\
\hline Median birth weight in g (IQR) & $1025(525)$ \\
\hline \multicolumn{2}{|l|}{ Gender } \\
\hline Female (\%) & $155(46.5 \%$ \\
\hline Male (\%) & $178(54.5 \%$ \\
\hline \multicolumn{2}{|l|}{ Ethnicity } \\
\hline White (\%) & $130(39.0 \%$ \\
\hline Mixed (\%) & $44(13.2 \%)$ \\
\hline Asian (\%) & $58(17.4 \%)$ \\
\hline Black (\%) & $74(22.2 \%)$ \\
\hline Unknown (\%) & $12(3.6 \%)$ \\
\hline Other (\%) & $15(4.5 \%)$ \\
\hline \multicolumn{2}{|l|}{ Mode of delivery } \\
\hline Vaginal delivery (\%) & $137(41.1 \%$ \\
\hline C-section (\%) & 196 (58.9\%) \\
\hline \multicolumn{2}{|l|}{ Ventilation } \\
\hline $\begin{array}{l}\text { Mean number of days requiring mechanical } \\
\text { ventilation prior to CPC or LS (SD) }\end{array}$ & $3.1(8.2)$ \\
\hline $\begin{array}{l}\text { Median number of days requiring mechanical } \\
\text { ventilation prior to CPC or LS (IQR) }\end{array}$ & $1(2)$ \\
\hline $\begin{array}{l}\text { Mean number of days CPAP (air) prior to CPC } \\
\text { or LS (SD) }\end{array}$ & $7.0(8.7)$ \\
\hline $\begin{array}{l}\text { Median number of days CPAP (air) prior to } \\
\text { CPC or LS (IQR) }\end{array}$ & $4(10)$ \\
\hline $\begin{array}{l}\text { Mean number of days CPAP (oxygen) prior to } \\
\text { CPC or LS (SD) }\end{array}$ & $9.3(14.8)$ \\
\hline $\begin{array}{l}\text { Median number of days CPAP (oxygen) prior } \\
\text { to CPC or LS (IQR) }\end{array}$ & $2(12)$ \\
\hline \multicolumn{2}{|l|}{ Feeding } \\
\hline $\begin{array}{l}\text { Mean number of days of donor breast milk } \\
\text { prior to CPC or LS (SD) }\end{array}$ & $8.3(8.9)$ \\
\hline $\begin{array}{l}\text { Median number of days of donor breast milk } \\
\text { prior to CPC or LS (IQR) }\end{array}$ & $6(8)$ \\
\hline $\begin{array}{l}\text { Mean number of days of maternal breast milk } \\
\text { prior to CPC or LS (SD) }\end{array}$ & $23.0(22.2)$ \\
\hline $\begin{array}{l}\text { Median number of days of maternal breast milk } \\
\text { prior to CPC or LS (IQR) }\end{array}$ & $17(25)$ \\
\hline $\begin{array}{l}\text { Mean number of days of formula prior to CPC } \\
\text { or LS (SD) }\end{array}$ & $3.3(9.0)$ \\
\hline $\begin{array}{l}\text { Median number of days of formula prior to CPC or LS } \\
\text { (IQR) }\end{array}$ & $0(2)$ \\
\hline $\begin{array}{l}\text { Mean number of days of breast feeding prior to CPC or } \\
\text { LS (SD) }\end{array}$ & $3.4(7.4)$ \\
\hline
\end{tabular}

Table 1 Demographics of infants included in the analysis ( $N=$ 333) (Continued)

\begin{tabular}{|c|c|}
\hline Demographics & Number \\
\hline $\begin{array}{l}\text { Median number of days of breast feeding prior } \\
\text { to CPC or LS (IQR) }\end{array}$ & $0(3)$ \\
\hline \multicolumn{2}{|l|}{ Antibiotic use } \\
\hline $\begin{array}{l}\text { Mean number of days of antibiotic use at } \\
\text { birth (SD) }\end{array}$ & $2.4(2.1)$ \\
\hline $\begin{array}{l}\text { Median number of days of antibiotic use at } \\
\text { birth (IQR) }\end{array}$ & $2(2)$ \\
\hline $\begin{array}{l}\text { Mean number of days of antibiotic use prior } \\
\text { to CPC or LS (SD) }\end{array}$ & $5.1(7.4)$ \\
\hline $\begin{array}{l}\text { Median number of days of antibiotic use prior } \\
\text { to CPC or LS (IQR) }\end{array}$ & $3(4)$ \\
\hline \multicolumn{2}{|l|}{ C. perfringens colonisation } \\
\hline Number colonised with C. perfringens (\%) & $98(29.4 \%)$ \\
\hline Mean number of days prior to CPC (SD) & $27.1(23.3)$ \\
\hline Median number of days prior to CPC (IQR) & $21(26)$ \\
\hline
\end{tabular}

Abbreviations: CPC C. perfringens colonisation, $L S$ Last sample, CPAP, Continuous positive airway pressure, $S D$ Standard deviation, IQR Interquartile range

combinations thereof, on the probability of colonisation. The results are shown in Fig. 3.

The dominant variable of the four appeared to be feeds with breast milk, with increased feeds being associated with the greatest shift towards low probability of $C$. perfringens colonisation. We theorised two modes of action for this association, with breast milk acting either directly (inhibiting the growth of $C$. perfringens) or indirectly (promoting the growth of other components of the gastro-intestinal microbiota which outcompete $C$. perfringens). We explored these possibilities in culture experiments as follows.

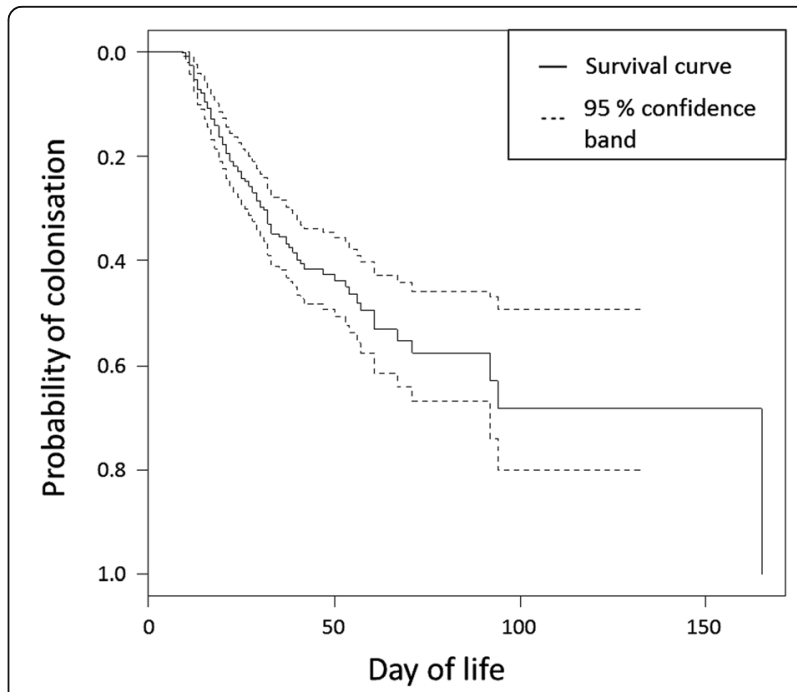

Fig. 1 Kaplan-Meier plot of probability of colonisation by C. perfringens over time. Data from our cohort of 333 infants. Dashed lines indicate the Hall-Wellner 95\% confidence bands 
Table 2 Results of the univariate survival analysis

\begin{tabular}{|c|c|c|c|c|c|c|c|c|c|}
\hline \multirow[t]{2}{*}{ Variable } & \multicolumn{5}{|c|}{ Quartiles } & \multirow{2}{*}{$\begin{array}{l}\text { Corrected } \\
P \text { value }\end{array}$} & \multirow[t]{2}{*}{ Coefficient } & \multirow{2}{*}{$\begin{array}{l}\text { Exponentiated } \\
\text { Coefficient (95\% Cl) }\end{array}$} & \multirow{2}{*}{$\begin{array}{l}\text { Risk change } \\
\text { for } 75 \% \\
\text { Quartile }\end{array}$} \\
\hline & $\overline{0 \%}$ & $25 \%$ & $50 \%$ & $75 \%$ & $100 \%$ & & & & \\
\hline Gestation (days) & 161 & 184 & 198 & 211 & 223 & 0.002 & 0.026 & $1.026(1.013-1.040)$ & 3.688 \\
\hline Birth weight (g) & 500 & 800 & 1025 & 1325 & 1890 & $<0.001$ & 0.001 & $1.001(1.001-1.002)$ & 2.788 \\
\hline Days of mechanical ventilation & 0 & 0 & 1 & 2 & 84 & 0.021 & -0.076 & $0.927(0.885-0.971)$ & 0.860 \\
\hline Days of CPAP oxygen & 0 & 0 & 2 & 12 & 80 & $<0.001$ & -0.039 & $0.962(0.947-0.977)$ & 0.626 \\
\hline $\begin{array}{l}\text { Days of maternal milk feeds } \\
\text { (non-breast) }\end{array}$ & 0 & 6 & 14 & 29 & 114 & $<0.001$ & -0.057 & $0.945(0.930-0.959)$ & 0.192 \\
\hline Days of breast feeds & 0 & 0 & 0 & 3 & 48 & 0.001 & -0.073 & $0.929(0.896-0.964)$ & 0.802 \\
\hline Days of antibiotic use & 0 & 2 & 3 & 6 & 79 & $<0.001$ & -0.116 & $0.89(0.848-0.934)$ & 0.497 \\
\hline
\end{tabular}

\section{Growth of $C$. perfringens in breast milk}

A $C$. perfringens isolate was grown in either nutrient rich medium (supplemented WCB broth) or breast milk, either as a monoculture or in co-culture with Bifidobacterium infantis which was chosen to represent a typical competing gut species, one that thrives on breast milk oligosaccharides
[23-25]. Both species grew in each substrate and under both culture conditions, and each grew significantly better in rich medium under monoculture than in breast milk ( $B$. infantis, $p=0.008, C$. perfringens, $p<0.0001)$. There was no significant difference in growth between the two species in the rich media when comparing the fold change between

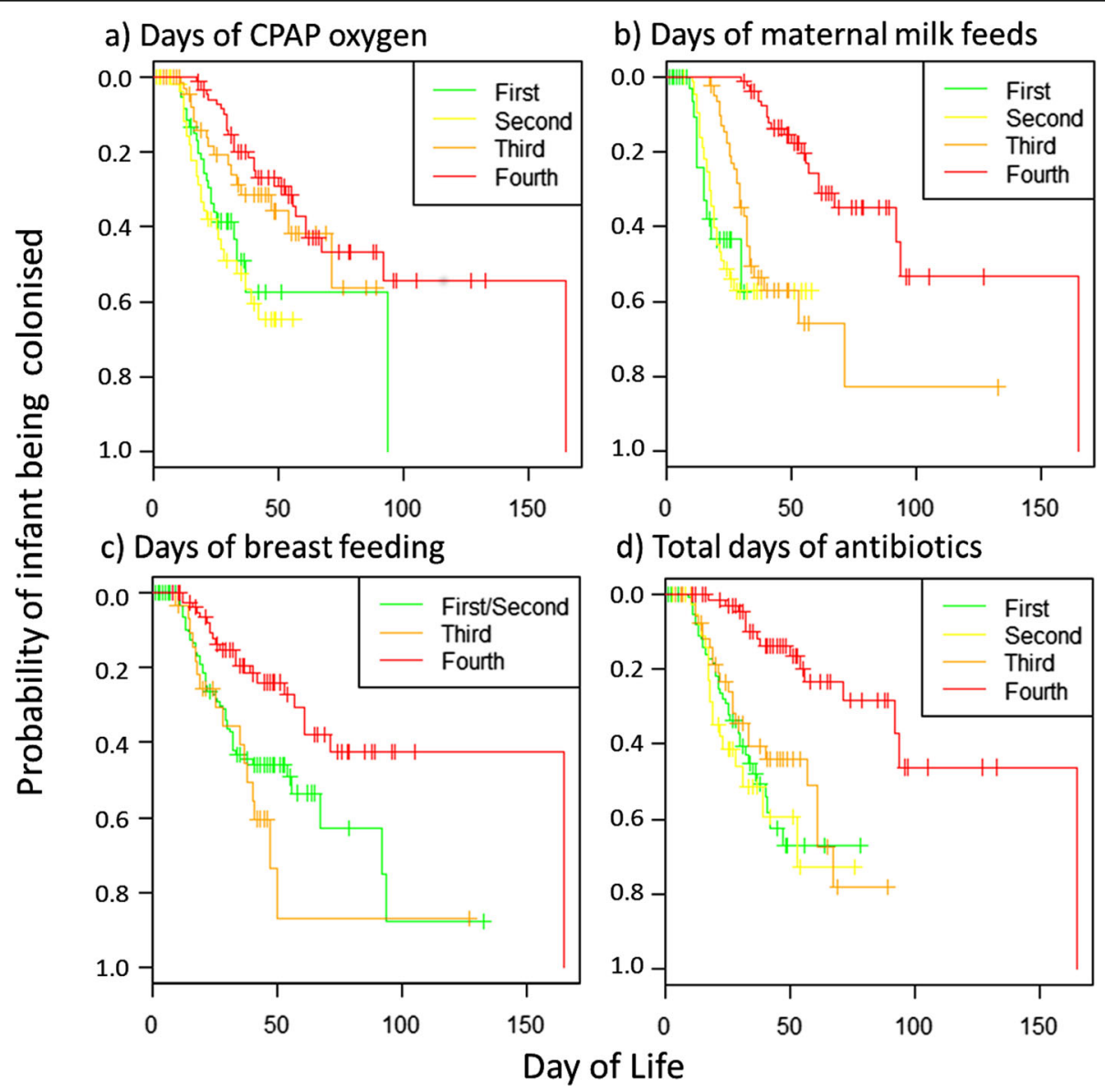

Fig. 2 Kaplan-Meier plots for each of the four significant factors in the multivariate model. $X$ axis shows the infant day of life. $Y$ axis shows the probability of colonisation for an infant when stratified according to quartiles (1st - 4th) of varying clinical factors: a) Days of CPAP oxygen, $\mathbf{b}$ ) Days of maternal milk feeds (excluding breast feeds), c) Days of breast feeding and d) Days of antibiotics usage. Colour codes for the quartiles are shown in the top right of each subplot 

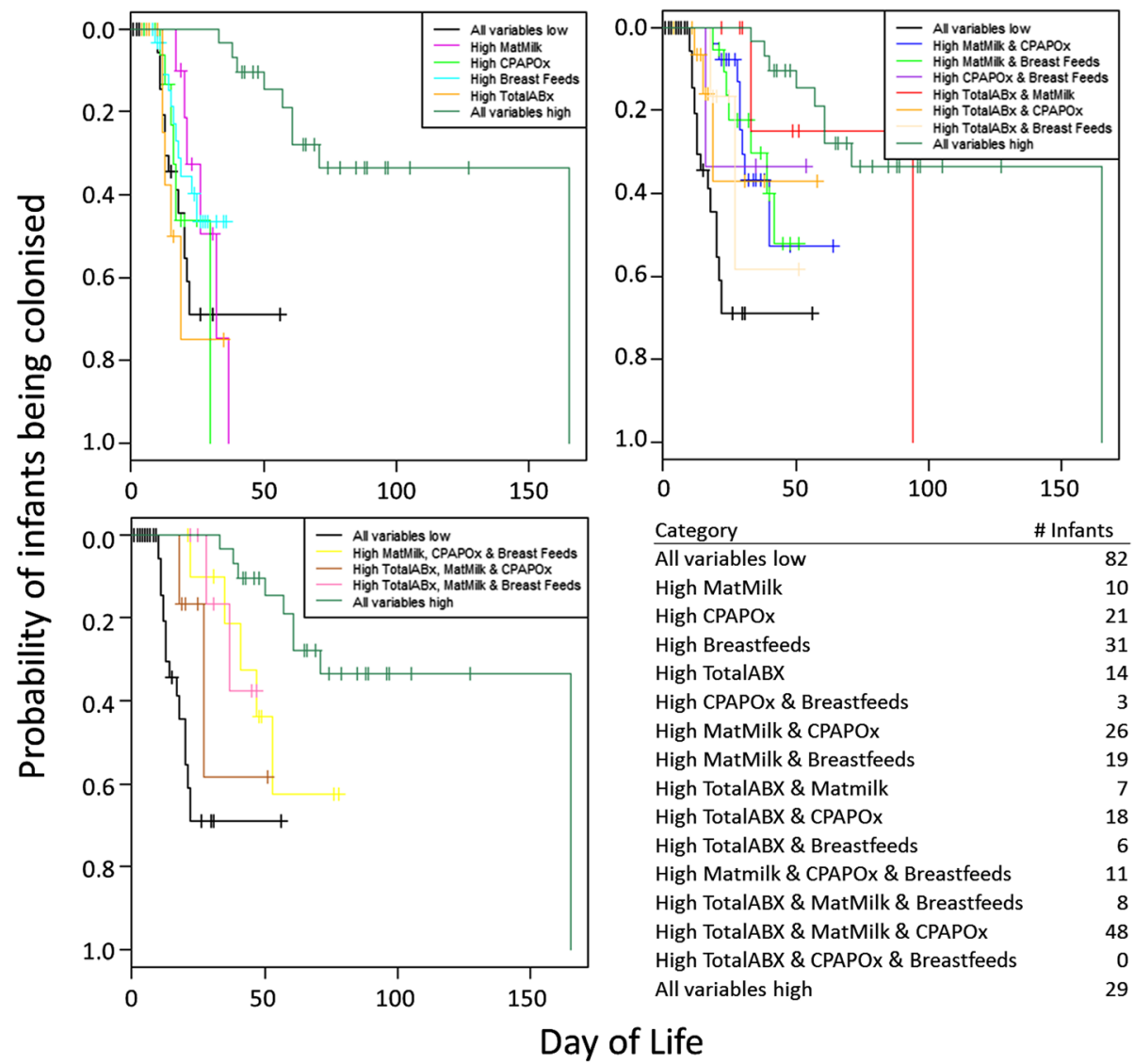

Fig. 3 Kaplan-Meier plots showing combinations of the four significant factors when split into low or high categories. For ease of comparability, 'All variables low' (<= median value for all four variables) and 'All variables high' (>median value for all four variables) are shown on each chart

inoculation and the 20-h timepoint. However, in breast milk $C$. perfringens grew at a significantly lower rate than $B$. infantis in monoculture $(p=0.003)$ and co-culture $(p=$ 0.0001). B. Infantis growth in breast milk was unaffected by mono- or co-culture, whilst growth of $C$. perfringens varied greatly but without significant association to breast milk type or mono- or co-culture (Fig. 4).

\section{Longitudinal carriage of $C$. perfringens}

We sought to establish whether mother's milk feeds or antibiotic treatments after the initial colonisation affected carriage of C. perfringens. 68 infants had at least one additional sample available after $C$. perfringens was first identified. Of these infants, $28 \%(n=19)$ yielded no further isolates. For $31 \%$ of infants $(n=21)$, all subsequent samples were positive, while the remaining $41 \%$ of infants $(n=28)$ tested positive in at least half of their additional samples. We recorded whether the infants recevied maternal milk feeds, CPAP oxygen or antibiotic treatment in the week after their initial colonisation, and found none of the factors to be significantly asscoated with multiple isolation events compared to a single isolation ( $p=0.75,0.88$ and 0.80 respectively).

\section{Toxic potential of $C$. perfringens isolates}

The harmful effects of $C$. perfringens arise in large part through the production of toxins. Of particular interest in the neonatal field is the potential for $C$. perfringens toxin to play a part in the pathogenesis of NEC $[4,5]$. We surveyed the $C$. perfringens isolates derived from our cohort for the presence of toxin genes through targeted PCR and found that a range of toxin genes were present. The presence of toxin genes in $C$. perfringens isolates during any point in their admission was scored for each neonate, allowing comparison of the toxic potential of the isolates prior to either discharge from the neonatal intensive care unit ("Control infants") or NEC incidence ("NEC Infants") (see Fig. 5).

Statistical analyses (Barnard's test and survival analysis) found no significant associations between the presence of toxin genes and the development of NEC. Given the infant numbers available in our cohort, Barnard's test would detect a proportional increase of 0.19 or greater in the occurrence of toxin in infants developing NEC compared to controls with 95\% confidence (assuming a one-sided test and $80 \%$ power). These results therefore do not support the hypothesis of NEC being 


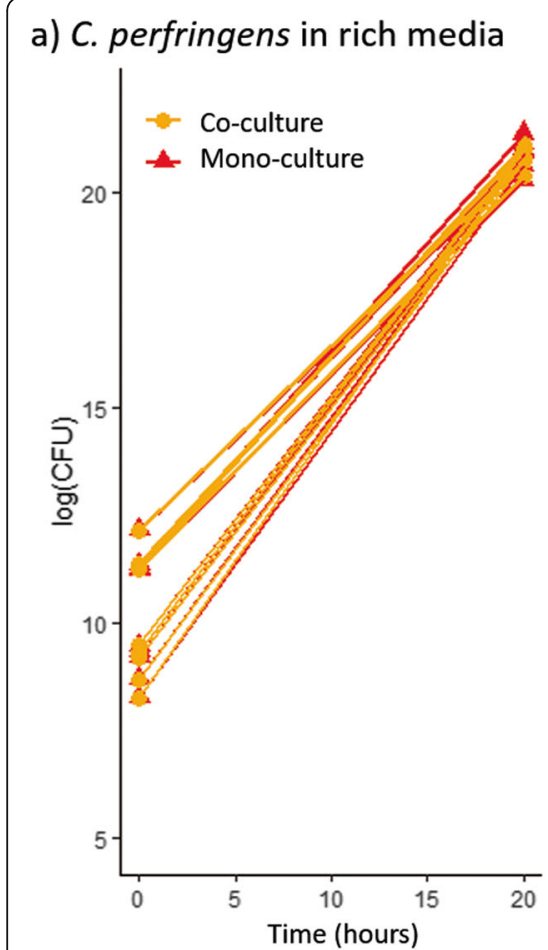

b) C. perfringens in breast milk

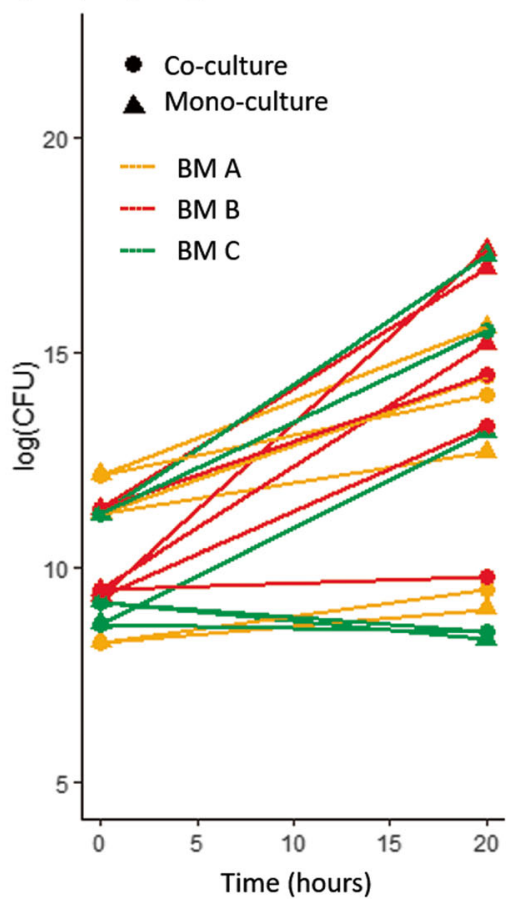

c) B. infantis in breast milk

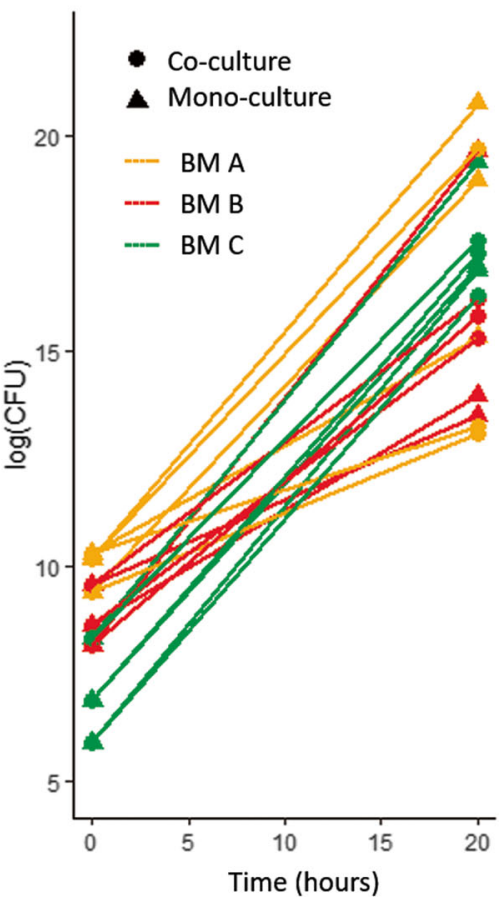

Fig. 4 C. perfringens and B. infantis growth in rich media and breast milk. Each bacterium was grown in each medium separately (monoculture) or together (co-culture). Experiments were performed in triplicate with three technical replicates (all replicas shown). BM=Breast milk, with three different donations being used in the experiments $(\mathbf{a}, \mathbf{b}$ and $\mathbf{c})$

associated with the prevalence of a particular toxin gene across our infant cohort. Overall, the most prevalent toxin genes in our neonatal $C$. perfringens isolates were $c p a, p f o A$, colA and $c p b 2$, which were found in 100, 64, 99 and $50 \%$ of isolates respectively.

\section{Discussion}

We have found that just under a third of infants (29.4\%) in our premature neonatal cohort were colonised with C. perfringens in their gut at some time during their stay in the neonatal intensive care unit (NICU), with duration of maternal milk feeds, antibiotic therapy, and continuous positive airway pressure with supplemental oxygen (CPAP oxygen) treatment exerting the strongest influence over probability of carriage. Our reported risk of colonisation with $C$. perfringens over time (approximately $25 \%$ at 3 weeks and $44 \%$ at 3 weeks) is very similar to findings in some other culture-dependent studies (35\% at 3 weeks of life [14], 46.1\% at 7 weeks of life [16]), although we are aware of one report of higher rates early in life (56.5\% at 1 week of life [26]).

We have found a significant inverse association between both duration of maternal milk feeds and breast feeding and probability of $C$. perfringens colonisation. This is in line with studies of term infants, which have reported that formula-fed infants have higher gut Clostridia counts compared to those who were breast-fed [27-29]. Bioactive constituents (immunoglobulins, lysozyme, lactoferrin, antimicrobial peptides, oligosaccharides) and commensal microbes in breast milk [30] actively protect against pathogen colonisation and invasion in the neonatal gut. An important mechanism of action is efficient metabolism of human milk oligosaccharides (HMOs) and subsequent acid production, for which $B$. infantis is especially adapted [23]. Many other gut commensal species, including Clostridium species $[24,25,31]$, cannot metabolise HMOs. Our growth experiments have shown that B. infantis significantly outperforms $C$. perfringens when grown in monoculture $(p=0.003)$ and co-culture $(p=0.0001)$ in breast milk. When the two species were cultured together, $C$. perfringens counts were not significantly reduced in the presence of $B$. infantis ( $p=0.1083)$ hence we saw no evidence of direct inhibitory action. This comparison could be further confounded by a range of other factors; potential competition by low abundance organisms derived from the breast milk (predominantly Staphylococci), the impact of $C$. perfringen toxins on the growth of Bifidobacteria and the effect of potential oxygen exposure which would impact $C$. perfringens more strongly than Bifidobacterium [32]. Direct inhibition by specific Bifidobacterium species has however been previously reported for growth of enteric pathogens (including C. perfringens) [33, 34] in vitro; for growth of 


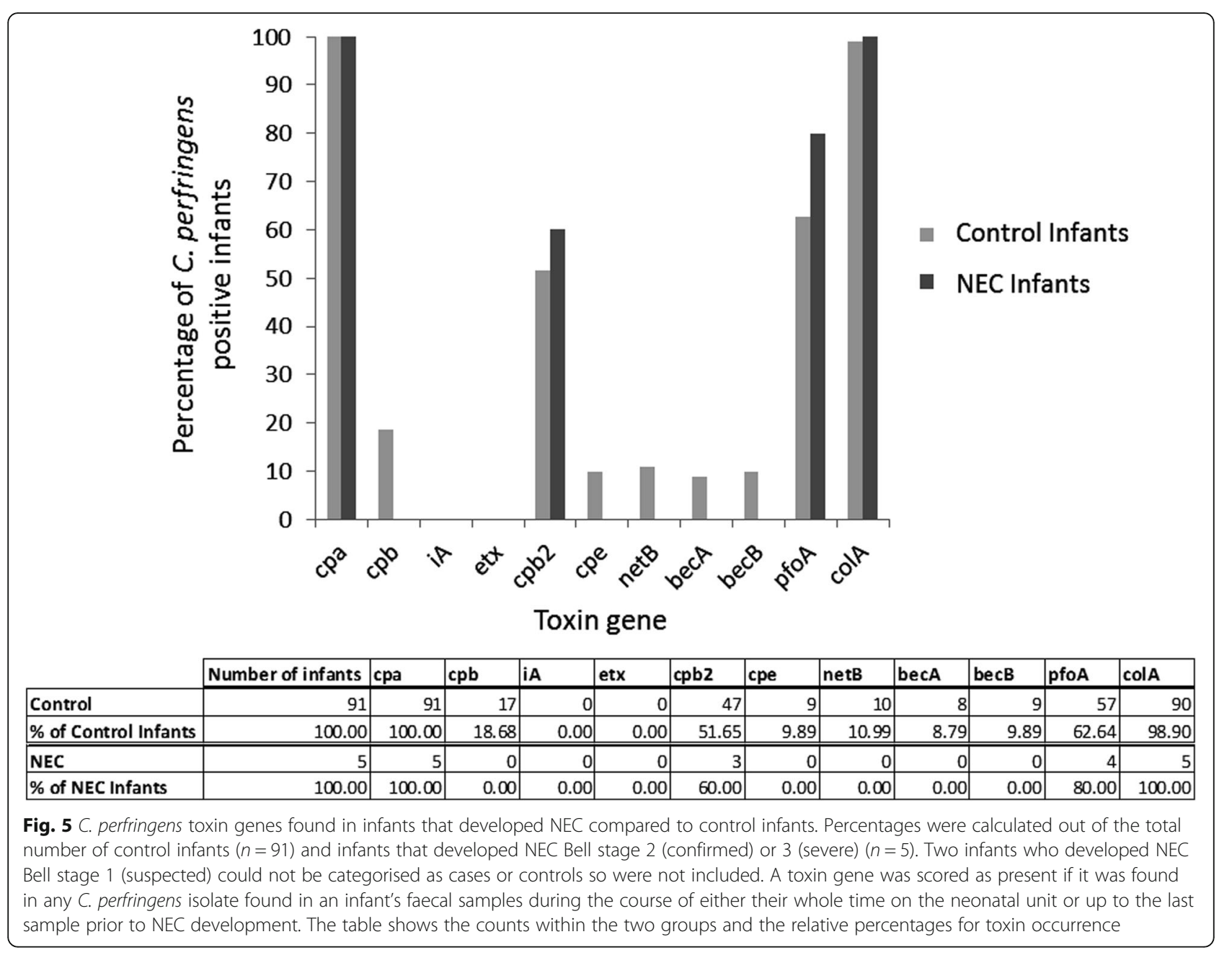

NEC-associated clostridia in a quail model [35]; and for clostridial growth in mouse models [36]. It has recently been reported that term infants who are carriers of $C$. perfringens have consistently lower levels of Bifidobacteria in their gut compared to noncarriers [37].

Interestingly, the impact of breast milk on $C$. perfringens carriage we report was only found for infants fed their own mother's milk (breast-fed or expressed into bottles), and not for those fed donor milk. In a recent systematic review [38], heat-treating donor milk to meet safety standards (normally by Holder pasteurization $-62.5^{\circ} \mathrm{C}$ for $30 \mathrm{~min}$, [21]), was shown consistently to reduce the level and/or activity of milk proteins including immunoglobulins, lactoferrin and enzymes, but had no effect on the lipid or saccharide content of milk. This suggests that donor milk may be inferior to maternal milk in an immunological capacity only, retaining qualities sufficient to influence C. perfringens colonisation patterns in some contexts. It has recently been demonstrated that neonatal mice can be protected from enteric infection by antibodies delivered through breast milk [39]. The absence of competing milk commensals in donor milk may perhaps further explain why in our study it failed to influence $C$. perfringens carriage in the way that maternal milk did.

Our results indicate that prolonged treatment with antibiotics or CPAP oxygen creates a hostile environment for C. perfringens in the preterm gut, reducing probability of carriage. C. perfringens may be particularly impacted by antibiotics due a rarity of multiple drug resistance genes [40] compared to other members of the neonatal gut microbiota [41]. A reduction in the abundance of C. perfringens in the preterm infant gut with antibiotic exposure has been observed in another cohort, although not reduced prevalence [16]. While antibiotic prophylaxis is routine in preterm neonatal care, it has been shown to significantly alter the gut microbiota in preterm infants $[42,43]$ and to be associated with adverse health outcomes including NEC, sepsis and death $[44,45]$; the benefits of avoiding putative $C$. perfringens-induced pathologies such as NEC must be weighed against the risks of inducing gut dysbiosis when considering antibiotic regimes. 
Similar to Ferraris et al., [16] we found that delivery mode had no effect on $C$. perfringens colonisation rates in our preterm neonatal cohort, in contrast to term infants [46-48].

Our analysis of the longitudinal carriage of $C$. perfringens found no association between maternal milk feeds, CPAP oxygen or antibiotic treatment in the week after the initial isolation of $C$. perfringens and continued carriage (defined as at least half of subsequent samples testing positive). Our study may however be underpowered to conclude whether these factors truly influence long term carriage as there was limited time for observation between colonisation and the infants being discharged from the NICU.

Our toxin typing results in a limited number of C. perfringens-associated NEC cases did not identify a specific toxin-mediated pathology. They have however provided evidence of a high occurrence of multi-toxigenic C. perfringens strains in the premature neonatal gut. The three most prevalent toxin genes in our neonatal $C$. perfringens isolates (cpa, pfoA and colA) can all be located to the same extracellular toxin gene cluster within a $250 \mathrm{~kb}$ region on the chromosome [49]. Of note was the presence of the plasmid-encoded beta 2 toxin gene, which was found in $50 \%$ of C. perfringens-positive infants. Although not fully elucidated, this toxin is strongly associated with porcine necrotic enteritis and is cytotoxic for human colorectal epithelial ( $\mathrm{CaCo}-2)$ cells [50]. Carriage of toxin genes, including beta2, is however observed in healthy human populations [51], hence the toxic phenotype is likely highly situational.

We detected other plasmid-encoded toxin genes in our neonatal isolates that have previously almost exclusively been detected in $C$. perfringens isolates from nonhuman species or cases of specific diseases: for example, the net $B$ gene and necrotic enteritis in poultry, and bec $A B$ genes and food poisoning in Japan. The most notable example of this however, is the presence of the beta toxin gene (denoting type $\mathrm{C} \mathrm{C}$. perfringens when found with the alpha toxin and no other major toxin) in 17 infants. Type C C. perfringens in humans is normally only isolated in cases of necrotic enteritis (Pigbel) or from healthy humans in endemic areas. We hypothesise that there is a low level circulation of "aberrant" toxin genes in the neonatal population, presumably acquired from the mother at birth, and detectable in this study due to large sample sizes (273 isolates screened). It is important to consider however, the high level of discordance between genotype and phenotype for many of the C. perfringens toxins.

\section{Conclusions}

We sought to understand the $C$. perfringens colonisation dynamics in a cohort of infants at high risk of mortality and morbidity from clostridia GI-induced pathologies.
We used a traditional culture method combined with PCR to demonstrate that toxigenic $C$. perfringens is part of the normal gut microbiota in preterm neonates and report that approximately $30 \%$ are colonised before they leave the NICU. We have identified perinatal factors that are able to significantly affect the probability of C. perfringens carriage: increased duration of maternal milk feeds, increased duration of CPAP oxygen treatment, and increased duration of antibiotic treatment, which correlated with protection from $C$. perfringens colonisation. We demonstrated an inhibitory effect of breast milk on the growth of $C$. perfringens in vitro and reaffirm the importance of maternal milk feeding in preterm neonatal care.

\section{Supplementary information}

Supplementary information accompanies this paper at https://doi.org/10. 1186/s12887-020-1976-7.

Additional file 1. C. perfringens toxin genes screened for in this study.

Additional file 2. PCR methods for toxin gene detection.

Additional file 3. Organisms grown in breast milk screening

\section{Abbreviations}

BHI: Brain heart infusion; BSM: Bifidus selective medium; CFU: Colony forming units; Cl: Confidence interval; CPAP: Continuous positive airway pressure; CPC: C. perfringens colonisation; CPE: C. perfringens enterotoxin; HMO: Human milk oligosaccharides; IQR: Interquartile range; LS: Last sample; MALDITOF: Matrix-assisted laser desorption/ ionization-time of flight: NEC: Necrotising enterocolitis; NICU: Neonatal intensive care unit; PCR: Polymerase chain reaction; SD: Standard deviation; TSC: Tryptose sulphite cycloserine; WCB: Wilkins-chalgren broth

\section{Acknowledgements}

We thank the microbiology laboratory at Charing Cross Hospital, Imperial College Healthcare NHS Trust London for use of the MALDI-TOF facilities. We thank the participants and their families for their contribution to the study.

\section{Authors' contributions}

AGS contributed to the manuscript, designed and conducted culture-based experimental work and performed the statistical analyses. EC contributed to the manuscript, designed the competition experiments and conducted the culture-based experimental work. KS contributed to the manuscript and the culture-based experimental work. HS and HT conducted the culture-based experimental work and assembled cohort data. JCSB contributed to the manuscript and designed and conducted the toxin PCR experiments. RAB and JSK contributed to the experimental design. All authors read and approved the final manuscript.

\section{Funding}

This work was supported by funding from the Winnicott Foundation; Micropathology Ltd.; Innovate UK; and the National Institute for Health Research (NIHR) Biomedical Research Centre based at Imperial Healthcare NHS Trust and Imperial College London. KS was funded during this work by an NIHR Doctoral Research Fellowship [NIHR-DRF-2011-04-128]. This article presents independent research funded by the NIHR. The views expressed are those of the authors and not necessarily those of the NHS, the NIHR, the Department of Health or other funders. Funding bodies had no role in the design of the study and collection, analysis, and interpretation of data and in writing the manuscript.

Availability of data and materials Not applicable. 


\section{Ethics approval and consent to participate}

The study "Defining the Intestinal Microbiota in Premature Infants" (ClinicalTrials.gov identifier NCT01 102738) was approved by West London Research Ethics Committee Two (National Health Service Health Research Authority), United Kingdom (reference number 10/H0711/39). Parents gave written informed consent for their infant to participate in the study.

\section{Consent for publication}

Not applicable.

\section{Competing interests}

The authors declare that they have no competing interests.

\section{Author details}

'Department of Infectious Disease Epidemiology, Imperial College London, London, UK. ${ }^{2}$ Department of Medicine, Section of Paediatrics, Imperial College London, London, UK. ${ }^{3}$ School of Life Sciences, University of Lincoln Lincoln, UK.

Received: 1 July 2019 Accepted: 12 February 2020

Published online: 18 February 2020

\section{References}

1. Stevens DL, Aldape MJ, Bryant AE. Life-threatening clostridial infections. Anaerobe. 2012;18(2):254-9.

2. Centers for Disease Control and Prevention. Food Safety Homepage, Foodborne IIIness A-Z, Clostridium perfringens. http://www.cdc.gov/ foodsafety/diseases/clostridium-perfringens.html 2015. Accessed Nov 2017

3. Neu J, Walker WA. Necrotizing enterocolitis. N Engl J Med. 2011;364(3) 255-64.

4. Blakey JL, Lubitz L, Campbell NT, Gillam GL, Bishop RF, Barnes GL. Enteric colonization in sporadic neonatal necrotizing enterocolitis. J Pediatr Gastroenterol Nutr. 1985:4(4):591-5.

5. Dittmar E, Beyer P, Fischer D, Schäfer V, Schoepe $H$, Bauer $K$, et al. Necrotizing enterocolitis of the neonate with Clostridium perfringens: diagnosis, clinical course, and role of alpha toxin. Eur J Pediatr. 2008;167(8): 891-5.

6. Heida FH, van Zoonen AG, Hulscher JB, te Kiefte BJ, Wessels R, Kooi EM, et al. A necrotizing Enterocolitis-associated gut microbiota is present in the meconium: results of a prospective study. Clin Infec Dis : Official Publication Infec Dis Soc Am. 2016;62(7):863-70

7. Sim K, Shaw AG, Randell P, Cox MJ, McClure ZE, Li M-S, et al. Dysbiosis anticipating necrotizing Enterocolitis in very premature infants. Clin Infec Dis: Official Publication Infec Dis Soc Am. 2015;60(3):389-97.

8. Warner BB, Deych E, Zhou Y, Hall-Moore C, Weinstock GM, Sodergren E, et al. Gut bacteria dysbiosis and necrotising enterocolitis in very low birthweight infants: a prospective case-control study. Lancet. 2016; 387(10031):1928-36.

9. Dobbler PT, Procianoy RS, Mai V, Silveira RC, Corso AL, Rojas BS, et al. Low microbial diversity and abnormal microbial succession is associated with necrotizing Enterocolitis in preterm infants. Front Microbiol. 2017:8:2243.

10. Penders J, Thijs C, van den Brandt PA, Kummeling I, Snijders B, Stelma F, et al. Gut microbiota composition and development of atopic manifestations in infancy: the KOALA birth cohort study. Gut. 2007;56:661-7.

11. Björkstén B, Sepp E, Julge K, Voor T, Mikelsaar M. Allergy development and the intestinal microflora during the first year of life. J Allergy Clin Immunol. 2001:108(4):516-20.

12. Martirosian G, Ekiel A, Aptekorz M, Wiechula B, Kazek B, Jankowska-Steifer E, et al. Fecal lactoferrin and Clostridium spp. in stools of autistic children. Anaerobe. 2011;17(1):43-5

13. Finegold SM, Molitoris D, Song Y, Liu C, Vaisanen ML, Bolte E, et al. Gastrointestinal microflora studies in late-onset autism. Clin Infect Dis. 2002; 35(Suppl 1):S6-s16.

14. Blakey JL, Lubitz L, Barnes GL, Bishop RF, Campbell NT, Gillam GL. Development of gut colonisation in pre-term neonates. J Med Microbiol. 1982:15(4):519-29.

15. Arboleya S, Binetti A, Salazar N, Fernández N, Solís G, Hernández-Barranco A, et al. Establishment and development of intestinal microbiota in preterm neonates. FEMS Microbiol Ecol. 2012;79(3):763-72.
16. Ferraris L, Butel MJ, Campeotto F, Vodovar M, Rozé JC, Aires J. Clostridia in premature Neonates' gut: incidence, antibiotic susceptibility, and perinata determinants influencing colonization. PLoS One. 2012;7(1):e30594.

17. Kiu R, Hall $L$. An update on the human and animal enteric pathogen Clostridium perfringens. Emerg Microbes Infect. 2018;7(1):141.

18. Uzal FA, Freedman JC, Shrestha A, Theoret JR, Garcia J, Awad MM, et al. Towards an understanding of the role of Clostridium perfringens toxins in human and animal disease. Future Microbiol. 2014;9(3):361-77.

19. van Asten AJAM, van der Wiel CW, Nikolaou G, Houwers DJ, Gröne A. A multiplex PCR for toxin typing of Clostridium perfringens isolates. Vet Microbiol. 2009:136(3):411-2.

20. Public Health England. UK standards for microbiology investigations: processing of faeces for Clostridium difficile: Available at: https:/www.gov.uk/government/ uploads/system/uploads/attachment_data/file/343912/B_10i1.5.pdf; 2014. Accessed Nov 2017.

21. Excellence NIfCaH. Donor milk banks: service operation. In: NICE Guidance CgC, editor.: Available at https://www.nice.org.uk/guidance/CG93/chapter/1Guidance; 2010. Accessed Nov 2017.

22. Kotsanas D, Carson JA, Awad MM, Lyras D, Rood JI, Jenkin GA, et al. Novel use of Tryptose sulfite Cycloserine egg yolk agar for isolation of Clostridium perfringens during an outbreak of necrotizing Enterocolitis in a neonatal unit. J Clin Microbiol. 2010;48(11):4263-5.

23. Sela DA, Chapman J, Adeuya A, Kim JH, Chen F, Whitehead TR, et al. The genome sequence of Bifidobacterium longum subsp. infantis reveals adaptations for milk utilization within the infant microbiome. Proc Natl Acad Sci U S A. 2008;105(48):18964-9.

24. Marcobal A, Barboza M, Froehlich JW, Block DE, German JB, Lebrilla CB, et al Consumption of human Milk oligosaccharides by gut-related microbes. J Agric Food Chem. 2010;58(9):5334-40.

25. Rockova S, Rada V, Marsik P, V/kova E, Bunesova V, Sklenar J, et al. Growth of bifidobacteria and clostridia on human and cow milk saccharides. Anaerobe. 2011:17(5):223-5.

26. Rotimi VO, Olowe SA, Ahmed I. The development of bacterial flora of premature neonates. J Hyg. 1985;94(3):309-18

27. Stark PL, Lee A. The microbial ecology of the large bowel of breast-fed and formula-fed infants during the first year of life. J Med Microbiol. 1982;15(2): 189-203.

28. Benno Y, Sawada K, Mitsuoka T. The intestinal microflora of infants: composition of fecal flora in breast-fed and bottle-fed infants. Microbiol Immunol. 1984;28(9):975-86.

29. Fallani M, Amarri S, Uusijarvi A, Adam R, Khanna S, Aguilera M, et al. Determinants of the human infant intestinal microbiota after the introduction of first complementary foods in infant samples from five European centres. Microbiology (Reading, England). 2011;157(Pt 5): 1385-92.

30. Fitzstevens JL, Smith KC, Hagadorn Jl, Caimano MJ, Matson AP, Brownell EA Systematic review of the human Milk microbiota. Nutr Clin Pract : Official Publication Am Soc Parenter Enteral Nutr. 2017;32:354-64.

31. Yu ZT, Chen C, Kling DE, Liu B, McCoy JM, Merighi M, et al. The principal fucosylated oligosaccharides of human milk exhibit prebiotic properties on cultured infant microbiota. Glycobiology. 2013:23(2):169-77.

32. Rolfe RD, Hentges DJ, Campbell BJ, Barrett JT. Factors related to the oxygen tolerance of anaerobic bacteria. Appl Environ Microbiol. 1978:36(2):306-13.

33. Hutt P, Shchepetova J, Loivukene K, Kullisaar T, Mikelsaar M. Antagonistic activity of probiotic lactobacilli and bifidobacteria against entero- and uropathogens. J Appl Microbiol. 2006;100(6):1324-32

34. Martinez FA, Balciunas EM, Converti A, Cotter PD, de Souza Oliveira RP. Bacteriocin production by Bifidobacterium spp. Rev Biotechnol Adv. 2013;31(4):482-8.

35. Butel MJ, Roland N, Hibert A, Popot F, Favre A, Tessedre AC, et al. Clostridial pathogenicity in experimental necrotising enterocolitis in gnotobiotic quails and protective role of bifidobacteria. J Med Microbiol. 1998;47(5):391-9.

36. Fukuda $\mathrm{S}$, Toh $\mathrm{H}$, Hase $\mathrm{K}$, Oshima K, Nakanishi $Y$, Yoshimura $\mathrm{K}$, et al. Bifidobacteria can protect from enteropathogenic infection through production of acetate. Nature. 2011:469(7331):543-7.

37. Nagpal R, Tsuji H, Takahashi T, Nomoto K, Kawashima K, Nagata S, et al. Gut dysbiosis following C-section instigates higher colonisation of toxigenic Clostridium perfringens in infants. Benefic Microbes. 2017;8(3):353-65.

38. Peila C, Moro GE, Bertino E, Cavallarin L, Giribaldi M, Giuliani F, et al. The Effect of Holder Pasteurization on Nutrients and Biologically-Active Components in Donor Human Milk: A Review. Nutrients. 2016:8(8):477. https://doi.org/10.3390/nu8080477. 
39. Zheng W, Zhao W, Wu M, Song X, Caro F, Sun X, et al. Microbiota-targeted maternal antibodies protect neonates from enteric infection. Nature. 2020; 577(7791):543-8.

40. Kiu R, Caim S, Alexander S, Pachori P, Hall LJ. Probing genomic aspects of the multi-host pathogen Clostridium perfringens reveals significant Pangenome diversity, and a diverse Array of virulence factors. Front Microbiol. 2017;8:2485.

41. Rose G, Shaw AG, Sim K, Wooldridge DJ, Li MS, Gharbia S, et al. Antibiotic resistance potential of the healthy preterm infant gut microbiome. Peerf. 2017;5:e2928.

42. Arboleya S, Sánchez B, Milani C, Duranti S, Solís G, Fernández N, et al. Intestinal microbiota development in preterm neonates and effect of perinatal antibiotics. J Pediatr. 2015;166(3):538-44.

43. Greenwood C, Morrow AL, Lagomarcino AJ, Altaye M, Taft DH, Yu Z, et al. Early empiric antibiotic use in preterm infants is associated with lower bacterial diversity and higher relative abundance of Enterobacter. J Pediatr. 2014;165(1):23-9.

44. Kuppala VS, Meinzen-Derr J, Morrow AL, Schibler KR. Prolonged initial empirical antibiotic treatment is associated with adverse outcomes in premature infants. J Pediatr. 2011;159(5):720-5.

45. Cotten CM, Taylor S, Stoll B, Goldberg RN, Hansen NI, Sanchez PJ, et al. Prolonged duration of initial empirical antibiotic treatment is associated with increased rates of necrotizing enterocolitis and death for extremely low birth weight infants. Pediatrics. 2009;123(1):58-66.

46. Penders J, Thijs C, Vink C, Stelma FF, Snijders B, Kummeling I, et al. Factors influencing the composition of the intestinal microbiota in early infancy. Pediatrics. 2006;118(2):511-21.

47. Gronlund MM, Lehtonen OP, Eerola E, Kero P. Fecal microflora in healthy infants born by different methods of delivery: permanent changes in intestinal flora after cesarean delivery. J Pediatr Gastroenterol Nutr. 1999; 28(1):19-25.

48. Biasucci G, Rubini M, Riboni S, Morelli L, Bessi E, Retetangos C. Mode of delivery affects the bacterial community in the newborn gut. Early Hum Dev. 2010;86(Suppl 1):13-5.

49. Katayama S, Dupuy B, Garnier T, Cole ST. Rapid expansion of the physical and genetic map of the chromosome of Clostridium perfringens CPN50. J Bacteriol. 1995;177(19):5680-5.

50. Fisher DJ, Miyamoto K, Harrison B, Akimoto S, Sarker MR, McClane BA. Association of beta2 toxin production with Clostridium perfringens type a human gastrointestinal disease isolates carrying a plasmid enterotoxin gene. Mol Microbiol. 2005;56(3):747-62.

51. Lakshminarayanan B, Harris HM, Coakley M, O'Sullivan O, Stanton C, Pruteanu $\mathrm{M}$, et al. Prevalence and characterization of Clostridium perfringens from the faecal microbiota of elderly lrish subjects. J Med Microbiol. 2013;62(Pt 3):457-66

\section{Publisher's Note}

Springer Nature remains neutral with regard to jurisdictional claims in published maps and institutional affiliations.

Ready to submit your research? Choose BMC and benefit from:

- fast, convenient online submission

- thorough peer review by experienced researchers in your field

- rapid publication on acceptance

- support for research data, including large and complex data types

- gold Open Access which fosters wider collaboration and increased citations

- maximum visibility for your research: over $100 \mathrm{M}$ website views per year

At $\mathrm{BMC}$, research is always in progress.

Learn more biomedcentral.com/submissions 